\title{
Türkiye'deki Kullanıcıların Bazı Alan Adları Üzerine Tercihlerinin Belirlenmesi: Bir Anket Uygulamas1
}

\author{
Serkan SAVAŞ ${ }^{1}$, Nurettin TOPALOĞLU², Osman GÜLER ${ }^{1}$ \\ ${ }^{1}$ Bilişim Teknolojileri Alanı, Kızılcahamam Mesleki ve Teknik Anadolu Lisesi, Ankara, Türkiye \\ ${ }^{2}$ Bilgisayar Mühendisliği Teknoloji Fakültesi, Gazi Üniversitesi, Ankara, Türkiye \\ serkan_savas@hotmail.com, nurettin@gazi.edu.tr, hanciosman@hotmail.com \\ (Geliş/Received: 31.01.2015; Kabul/Accepted: 08.05.2015) \\ DOI: $10.17671 / \mathrm{btd} .20505$
}

\begin{abstract}
Özet- TÜVAKA tarafindan 1990 yılında alınan kararlar ile birlikte Türkiye'de kullanılmakta olan ikincil düzey alan adı sistemi, günümüzde internet kullanıcılarının akıllarında soru işaretleri oluşturmuştur. Türkiye'de yerleşik bazı şirketler, uzunluğundan dolayı com.tr uzantılı adresler yerine ABD'ye ait com uzantılı adresleri tercih etmektedir. Bu durumda şirketlerin alan adlarına bakarak hangi ülkeye ait oldukların ilk bakışta anlamak oldukça zor olmaktadır. Buradan yola çıkarak, internet alan adları ve Türkiye'de kullanılan ikincil düzey alan adı sistemi incelenmiştir. Ülkemizde de artık ülke kodu birinci derece alan adı sisteminin kullanılabilmesi ve gerektiğinde bazı kurumlara ayrıcalık tanınarak jenerik birinci derece alan adını kullanmalarını sağlamanın mümkün olduğu söylenebilir. Ülkemizde internet kullanım amaçlarını araştırmak ve alan adı algısını incelemek üzere 500 internet kullanıcısına uygulanmış ve sonuçları açıklanmıştır. Anket sonucunda yüzde 77 oranla kullanıcılar ülke kodu birinci derece alan adını tercih etmişlerdir.
\end{abstract}

Anahtar Kelimeler - internet, alan adı, jenerik birinci derece alan adı, ülke kodu birinci derece alan adı, DNS

\section{The Determination of Users' Preferences on Some Domain Names in Turkey: A Survey Application}

\begin{abstract}
The second level domain name system which is started to be used in Turkey after the decision in 1990 by TÜVAKA created questions in user minds nowadays. Some companies in Turkey don't choose .com.tr extension because of its long form and they prefer .com extensions which belong to the U.S.A. In this case, it is hard to understand which companies belong to which country just by seeing the domain name. From this point, the internet domain names and second level domain name systems used in Turkey have been examined. It is understood that use of the country code is possible for the top level domain name system in Turkey. Also it is possible for some institutions as privilege that they can use generic top level domain names. A survey has been carried out to understand the aims of the internet usage and the perception of the domain names applied to 500 internet users and the survey results have been announced. It is understood that 77 percent prefer the country code top level domain name.
\end{abstract}

Keywords - internet, domain name, generic top level domain name, country code top level domain name, DNS

\section{GİRIŞ̧ (INTRODUCTION)}

Internetsiz hayat artık hayal dahi edilememektedir. 2014'ün üçüncü çeyreğinde Türkiye'de yaklaşı 40 milyon genişbant internet abonesi bulunmaktadır. Bunların yaklaşık 31,1 milyonu mobil internet abonesi, geri kalanı ise xDSL, Kablo, Fiber vd. internet aboneleridir [1]. Ev kullanıcıları, işyerleri ve mobil kullanıcılarla birlikte internet kullanımı da, dijital çağ olarak adlandırılan çağımızda katlanarak artmaktadır. Internet günlük hayatımızda bu kadar önemli yer almışken onun önemli bir bileşeni olan alan adı sisteminin (domain name system - DNS) istikrarını sağlamak çok önemlidir. Çünkü DNS, yönlendirme protokolünde kullanılan Internet Protokolü (IP) numaralarını insanlar tarafından daha kolay hatırlanabilir ve okunabilir alan adlarına çevirmek için kullanılır. Örneğin DNS sayesinde "157.166.255.19" yerine cnn.com kullanılabilir [2]. İnternet üzerindeki alan adı modelleri ülkeler arasında farklılıklar göstermektedir. Türkiye'deki kullanıcıların yurtdışındaki siteleri kullanmaları sırasında gördükleri uzantı farklılıkları akıllarda soru işaretleri 
oluşturmaktadır. Dünyanın en çok kullanılan arama motoru [3] Google'ın bazı ülkelerde kullandığg adreslere Tablo 1'e bakarak ülkeler arası alan adı modeli farklılıklarını görebiliriz.

Tablo 1. Google ülke alan adları (Google country domain names)

\begin{tabular}{|l|l|}
\hline \multicolumn{1}{|c|}{ Ülke } & \multicolumn{1}{c|}{ Adres } \\
\hline Türkiye & Google.com.tr \\
\hline Afganistan & Google.com.af \\
\hline Angola & Google.it.ao \\
\hline Avusturya & Google.at \\
\hline Azerbaycan & Google.az \\
\hline Belçika & Google.be \\
\hline Danimarka & Google.de \\
\hline Fransa & Google.fr \\
\hline Güney Afrika & Google.co.za \\
\hline İngiltere & Google.co.uk \\
\hline İtalya & Google.it \\
\hline Pakistan & Google.com.pk \\
\hline Rusya & Google.ru \\
\hline Uganda & Google.co.ug \\
\hline Ukrayna & Google.com.ua \\
\hline Zambiya & Google.co.zm \\
\hline
\end{tabular}

Ülkemizdeki adres yapısını incelediğimizde, 1990 yılında TÜVAKA (Türkiye Üniversiteler ve Araştırma Kurumları Ağı) tarafindan alınan karar doğrultusunda ikinci düzey alt alan adı modelinin benimsendiği görülmektedir [4]. Ancak o tarihte alınan karar günümüz için ne kadar geçerlidir? Ülkemizdeki insanların algıları nasıldır? Bu çalışmada alan adı (domain) sistemi açıklanmış ve ülkemiz tarafından kullanılan ikinci düzey alt alan adı modelinin tercih edilme durumu hakkinda anket uygulanıp sonuçları tartışılmıştır. Ayrıca alan adı modellerinin olumlu ve olumsuz yönlerine değinilmiş ve karma bir alan adı modelini benimseyen hibrid model kullanımı önerilmiştir.

\section{DNS (Domain Name System - Alan Adı Sistemi)}

Alan adları, internet üzerinde bilgisayarların birbirlerine ulaşmasını sağlayan IP adresleme sisteminin daha kolay kullanılabilmesi ve akılda kalabilmesi için kelimelerle ifade edilen halidir [2].

IP adresleme sisteminde her bilgisayar için ayrı olmak üzere 32 bitlik bir sayı dizisi bulunmaktadır. Bu sayılar, gerek hatırlamak gerek de yazmada kolaylık sağlamak amacıyla 4 bölüm olarak, sekizli ondalık sistemde (örneğin 212.174.189.120) yazılır [5,6,7]. Sekizli ondalık halindeki bu 4 kısım 0 ile 255 arasında değer alır. IP adresi, ağ üzerinde bulunan makinenin adresini ifade eder. $\mathrm{Bu}$ adres ile bir makine başka bir makineye ulaşma imkânı bulur. TCP/IP protokolü kullanılan bir ağda her bilgisayar bir IP adresi kullanmak zorundadır. IPv4 (32 bit) ve IPv6 (128 bit) olmak üzere iki çeşit IP adresi sistemi vardır. Günümüzde çoğunlukla 32 bitlik (IPv4) adresleme kullanılmakta ancak internetin yaygınlaşmasıyla birlikte IPv4 adreslerini tükenmektedir [8]. Bu nedenle IPv6 adreslerinin kullanılmasına yönelim olmuştur. IPv6 adresleri, deyim yerindeyse neredeyse sınırsız adresleme imkânı sunacaktır.

DNS aslında bir TCP/IP servis protokolüdür ve internete bağlı tüm birimlerin yerel olarak bir ağaç yapısı içinde gruplandırılmasını sağlar. Böylece internet sistemi içerisinde makineler birbirlerine kolaylıkla ulaşım sağlayabilmektedirler. DNS sistemi olmadan, ticaret, finans, endüstriyel süreçler, ulaşım, sağlık vb. günlük gerçekleştirdiğimiz tüm aktivitelerin teknolojik ayağ1 mümkün olmayacaktır. İnternet ortamında IP yönlendirme işlemi en önemli işlem iken, günümüzde artık alan adı sisteminin önemi ikinci dereceye yerleşmiştir [9].

Alan adları TLDs (Top Level Domains) ve SLDs (Second Level Domains) olmak üzere iki kısımdan oluşur.

Tablo 2. DNS Hiyerarşisi (DNS Hierarchy)

\begin{tabular}{|l|c|}
\hline DNS Hiyerarşisi & Örnek Alan \\
\hline Kök seviye & . \\
\hline Birincil seviye & gov.tr \\
\hline İkincil seviye & meb \\
\hline Alt Alan & katem \\
\hline
\end{tabular}

Yukarıdaki tabloda, www.katem.meb.gov.tr alan adında "gov. tr" birincil seviye alan adı, "meb" ikincil seviye alan adıdır. "Katem" ise meb alanı içerisinde bir alt alandır. Birincil seviye alan adları da gTLDs (Generik Top Level Domains) ve ccTLDs (Country Code Top Level Domains) olmak üzere ikiye ayrılır. Jenerik birinci derece alan adları, esas itibariyle ICANN (Internet Corporation for Assigned Names and Numbers - İnternet Tahsisli Sayılar ve İsimler Kurumu) ve ICANN tarafından yetkilendirilmiş kuruluşlar tarafindan tahsis edilmektedir. "ICANN, tüm İnternet kullanıcılarının geçerli adresler bulabilmelerini sağlamak üzere evrensel çözülebilirlikten emin olunması için DNS'in teknik unsurlarının yönetiminin koordinasyonundan sorumludur" [10]. TLD ya da gTLD deyimleri, Jenerik birinci derece alan adlarını belirtmek amacıyla kullanılmaktadır. $\mathrm{Bu}$ alan adları, dünya çapında yaygın şekilde kullanılan ve herkes tarafindan tescil ettirilmesi serbest olan alan adlarıdır. Ülke kodu alan adları ise her ülkenin kendi mevzuatına göre yetkilendirilmiş kuruluşlarca tahsis edilmektedir [11].

Ülkemizde kullanılan ikincil düzey alan adları [12];

“.com.tr”: Ticari özel ve tüzel kişiliklere,

".net.tr": İnternete ilişkin erișim hizmeti, internet üzerinden web, portal, tarama, e-posta vb. katma değerli, geniş ölçekli hizmetler ve uygulama servis sağlayıcılığ hizmetleri veren kurum ve oluşumlara,

“.info.tr”: Ticari özel ve tüzel kişiliklere,

“.biz.tr”: Ticari özel ve tüzel kişiliklere,

“.org.tr”: Vakıf, dernek, sivil toplum örgütü vb. kuruluşlar ve oluşumlara,

“.web.tr”: Kişisel ve kurumsal başvurunun (genel) yapılabildiği ve 'ilk gelen alır', ve 'alan adı - kişi/kuruluş 
adı ilişkisi aranmaz' ilkeleri ile ad tahsisi yapılan alt alan adlarına,

"gen.tr": Kişisel ve kurumsal başvurunun (genel) yapılabildiği ve 'ilk gelen alır' ve 'alan adı - kişi/kuruluş adı ilişkisi aranmaz' ilkeleri ile ad tahsisi yapılan alt alan adlarına,

“.av.tr”: Serbest avukatlar, hukuk büroları ve avukatlık ortakliklara,

".dr.tr.": T1p doktorları, doktor ortaklıkları, hastaneler ve Sağlık Bakanlığı birinci basamak sağlık kuruluşlarına,

“.name.tr”: T.C. vatandaşları ile Türkiye'de yaşayan yabancı uyruklu kişilerin kişisel kullanımına,

".tel.tr": Türkiye'de yaşayan kişiler ile faaliyet gösteren kuruluşların, Türkiye'de kullandıkları her türlü telefon numarasina,

“.gov.tr”: T.C. Devlet kurum ve kuruluşlarına,

“.bel.tr”: T.C. İl, ilçe ve belde belediye teşkilatlarına,

“.pol.tr”: T.C. Emniyet teşkilatına,

".mil.tr": T.C. Askeri kurum ve kuruluşlarına,

“.k12.tr”: T.C. MEB'ce onaylanmış ilköğretim ve liselere,

".edu.tr": T.C. YÖK tarafindan onaylanmış yükseköğretim kurumlarına, tahsis edilmiştir.

Ülke kodu birinci derece alan adı uzantıları, domainin bir bölgeye ait olduğunu gösteren ektir. Amerika Birleşik Devletleri (ABD) hariç hemen hemen diğer tüm ülke adresleri, o ülkenin ISO3166-1 ülke kodu ile bitmektedir. Ülkemizde ".com" uzantısı alınırken genel bir uzantı olduğu düşünülse de aslında alınan adres ABD bölgesine ait bir alan adı haline gelmektedir. Ancak bu, sonunda ".tr" uzantısı olmadığı için yapı itibariyledir ve dolayısıyla böyle bir alan adı aldığımızda ABD'ye bağl bir domain alınmış olmamaktadır. ABD'den başka ISO3166-1 kodlarına uymayan ülkeye örnek vermek gerekirse İngiltere (United Kingdom)'nin ISO3166-1 kodlarına göre uzantısı “.gb” ancak İngiltere'nin bölgesel uzant1s1 ".uk"dir.

Ülkemizde 1990 yılında TÜVAKA tarafindan alınan karar sonrasında kullanılmakta olan alan adı sistemi, internet kullanıcılarının akıllarında soru işaretleri oluşturmaktadır. İnternette 'neden 'alanadı.tr' şeklinde adres alamıyoruz?" gibi sorularla araştırmalar yapılmaktadır. Pek çok forumda bu sorular sorulmakta ve cevaplar aranmaktadır [13-22]. Hatta Türkiye'de, Turks and Caicos Adaları'na verilen bir alan adı uzantısı olan ".tc" uzantısı daha satışa çıkmış ve kullanılmaya başlanmıştır. "TC" ülkemizde Türkiye Cumhuriyeti'nin k1saltması olarak kullanılmaktadır. Türkiye'den insanlar ".tc" alan uzantısını almaktadır çünkü Turks and Caicos Adaları'nda nüfus 45 Bin civarında olup, ülkedeki internet kullanımı oldukça düşük seviyededir. Bunu bir firsat olarak bilen ve bu ülke uzantısının haklarını elinde bulunduran İngiliz Adams Names şirketini satın alan Alman kökenli INTERSTATE şirketinin Türkiye'de kurduğu TCNET Internet Şirketi, bu uzantıyı ülkemizde de kullanıcılara satma kararı almıştır [23,24]. Bunun sonucu olarak da ülkemizde şu anda ".tc" uzantılı alanlar da kullanılmaktadır. Bundan farklı olarak ülkemizde "www.tsk.tr" ve "www.nic.tr" alanları, ülke kodu birinci derece alan adı sistemini benimsemişlerdir. $\mathrm{Bu}$ da göstermektedir ki, aslında bu model adresleme yapısının ülkemizde de kullanılabilirliği bulunmaktadır. Bu çalışmada, her iki adresleme yapısının da kullanıldığı, bazı kurum ve kuruluşlara ayrıcalık tanınan (Devlet, Askeri, Üniversite) hibrid bir adresleme yap1s1 önerilmektedir. Böylece kullanıcılar istediğinde ".tr" uzant1lı adresler alabilecekken, bazı kurumları diğerlerinden ayırt etmek amacıyla jenerik birinci derece alan adı uzantılarını da kullanılabilirler.

Ülke kodu birinci derece alan adı sistemi kullanıldığında akla bazı sorular gelebilecektir. Örneğin bir üniversite adı ile bir firma adının aynı olması durumunda hangisi istediği ismi kullanabilecektir. Böyle durumlarda yukarıda bahsedilen bazı kurumlara tanınabilecek jenerik birinci derece alan adı kullanımı hakkının yanı sıra, hali hazırda da kullanılan "ilk gelen ilk alır"[4] prensibi de kullanılabilir.

Ülkemizdeki kullanıcıların alan adları hakkındaki algılarını araştırmak amacıyla bir anket uygulaması gerçekleştirilmiştir. Anket soru ve sonuçları bu çalışmanın üçüncü bölümünde değerlendirilmiştir.

\section{ANKET UYGULAMASI (SURVEY APPLICATION)}

Başta Ankara-Kızılcahamam'daki internet kullanıcıları ve Gazi Üniversitesi Bilişim Enstitüsü öğrencileri olmak üzere internet kullanan bağımsız 500 (beş yüz) kişiye anket uygulanmıştır. Anket içerisinde kullanıcıların internet kullanma sıklıkları, amaçları, internet ortamına duydukları güven ve alan adı algıları gibi konular incelenmiştir. Anket yeni geliştirilmiş bir anket olup, Cronbach's Alpha değeri şekil 1'de görüldüğü gibi 0,6 çıkmış ve uygulanabilir bir anket olduğu sonucuna ulaşılmıştır.

Tablo 3. Uygulanan anket için Cronbach's Alpha sonucu (Cronbach's Alpha result for the applied survey)

\begin{tabular}{|c|c|c|c|}
\hline \multicolumn{4}{|c|}{ Durum İşlem Özeti } \\
\hline & & Say1 & $\%$ \\
\hline \multirow{3}{*}{ Durumlar } & Geçerli & 500 & 100 \\
\hline & Hariç tutulan & 0 & 0 \\
\hline & Toplam & 500 & 100 \\
\hline \multicolumn{4}{|c|}{ Güvenirlik İstatistikleri } \\
\hline \multicolumn{2}{|c|}{ Cronbach's Alpha } & \multicolumn{2}{|c|}{ Eleman Sayıs1 } \\
\hline \multicolumn{2}{|c|}{,600 } & \multicolumn{2}{|c|}{9} \\
\hline
\end{tabular}

Anket sonuçlarına göre ortaya çıkan durum şöyle olmuştur. 


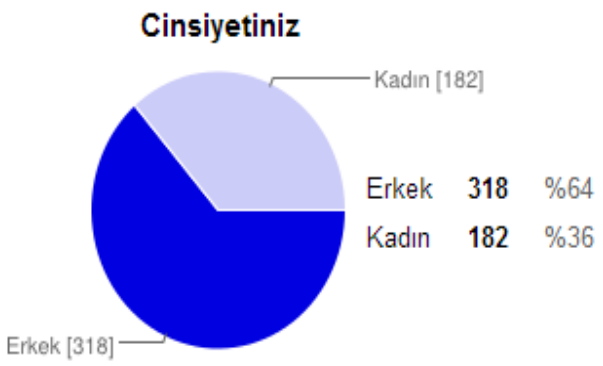

(a)

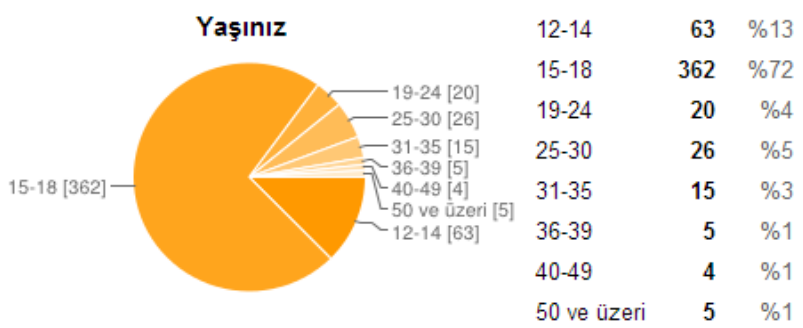

(b)

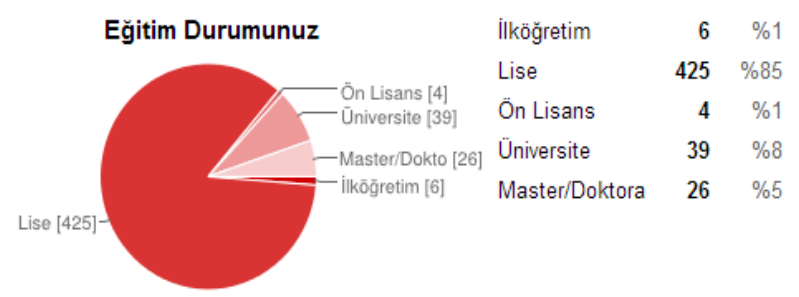

(c)

Şekil 1. Cinsiyet, yaş ve eğitim durumu dağglımı (Gender, age and education status distribution)

Şekil 1a'da görüldüğü gibi ankete katılan internet kullanıcılarından \%64 ile çoğunluk grubunu "erkek" kullanıcılar oluşturmuştur. Toplam 318 erkek kullanıcı ankete katılmıștır. Ankete katılan kadın kullanıcı oranı ise \%36 olup toplamda 182 kadın kullanıcı anketi doldurmuştur. 500 kullanıcının yaş grubu dağılım gösterse de şekil 1b'de görüldüğü gibi \%72 oranla 15-18 yaş grubu belirgin bir üstünlüktedir. Dijital nesil olarak adlandirilan grubun bu ankette 362 kullanici ile çoğunluğu oluşturması, yeni neslin internet kullanım amaçları, sanal dünyaya güven durumları ve alan adı algıları ile ilgili önemli bilgiler vermesi açısından faydalı olmuştur. Kullanıcıların eğitim durumları ise yaş durumuyla paralellik göstermiştir. Lise düzeyinde kullanıcıların \%85 oran ile en ön sırada bulunduğu şekil $1 c$ 'de görülmüştür. Üst yaş gruplarından da lise düzeyinde eğitim seviyesinde bulunan kullanıcılar olmuştur.

Interneti kullanma sıkığınız

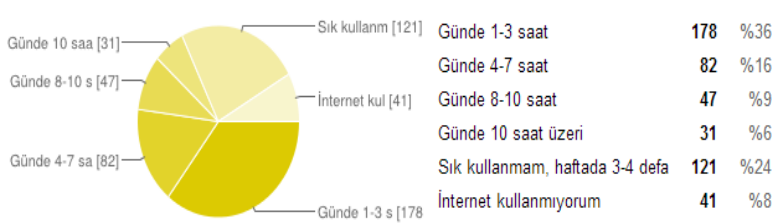

Interneti mobil cihazlardan (akıllı telefon, pda vb.) kullanırım

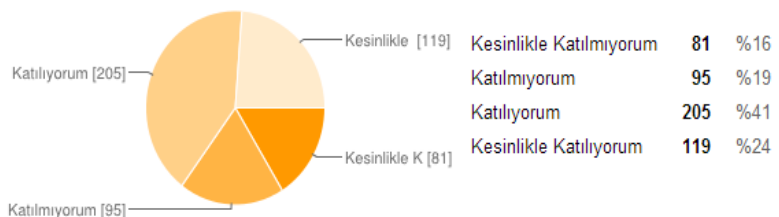

Şekil 2. İnternet kullanım sıklığı ve mobil cihazlar (The frequency of Internet usega and mobile devices)

Şekil 2'de görüldüğü gibi ankete katılan kullanıcıların toplamda \%68 gibi büyük bir çoğunluğu her gün internet kullanmaktadır. 338 kullanıcı içerisinden 178 adedi günde 1-3 saat internet kullanımı ile çoğunluğu oluşturmaktadır. 31 kullanıcı ise günde 10 saat üzerinde internet kullanımı ile internetin hayatlarının ayrılmaz bir parçası olduğu gerçeğini göstermişlerdir. Anketi cevaplandıran kullanıcılar içerisinden $\% 8$ oranında kişi ise interneti kullanmadığını belirtmiştir. Bir diğer anket sorusu ise günümüzün olmazsa olmazları haline gelmeye başlayan mobil cihazlar ile ilgili olmuştur. Kullanıcılardan toplamda \%65 oranla büyük bir çoğunluğu, interneti mobil cihazlardan da kullandığını belirtmiştir. 324 kullanıcı interneti mobil cihazlardan da kullanarak artık mobil cihazların günlük hayatımızdaki önemini de göstermiştir. Kesinlikle katılmıyorum seçeneğini işaretleyen kişiler içerisinden 41 tanesini de internet kullanmayan kişiler olduğunu varsaydığımızda, geriye kalan toplamda 135 kullanıcının masaüstü/dizüstü gibi bilgisayar kullanıcıları olduğunu düşünebiliriz. Bunun sonucunda da internet kullanımının gittikçe mobil kullanıcılar yönünde şekillendiği ortaya çıkmıştır.

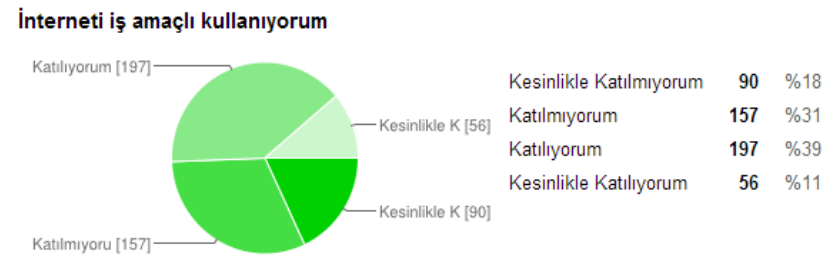

İnterneti sosyal/eğlence amaçlı kullanıyorum

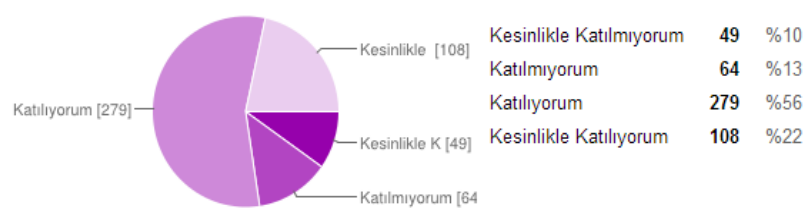

İnterneti eğitim amaçlı kullanıyorum

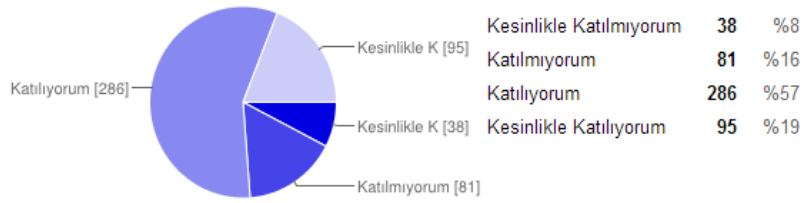

Şekil 3. İnternet kullanım amaçları (Internet usage purposes)

Ankette internet kullanıcılarına, kullanım amaçlarıyla ilgili sorular da sorulmuştur. Şekil 3'te görüldüğü gibi iş amaçlı internet kullanımı kullanıcılar arasında toplamda yarı yarıya olurken, kullanım amaçları ağırlıkla 
sosyal/eğlence ve eğitim için kullanım olmuştur. İş amaçlı internet kullananların sayısı 253 olurken geriye kalan 247 kullanıcı interneti iş amaçlı kullanmamaktadır. İnterneti sosyal/eğlence amaçlı toplamda 387 kullanıcıyla ve eğitim amaçlı kullanan toplamda 381 kullanıcı ile belirgin bir fark görülmüştür. Buradan sosyal paylaşım sitelerinin günlük hayatımızdaki önemi de ortaya çıkmaktadır.

İnterneti üzerinden kitap, makale vb. okurum
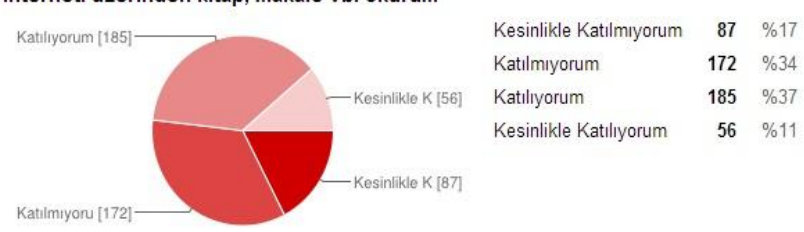

Araştırmalarımı internet üzerinden yaparım

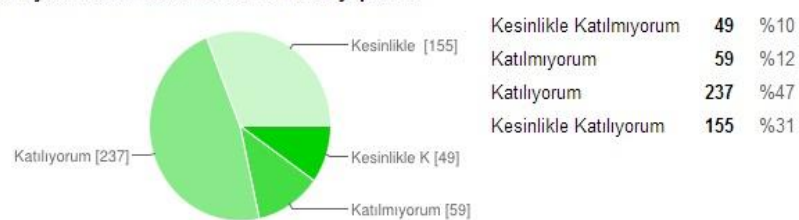

Şekil 4. Araştırma ve eğitim amaçlı internet kullanımı (Internet usage for research and education purposes)

Anketi cevaplayan internet kullanıcıları, internet üzerinden makale ve kitap okuma sorusunda yaklaşık olarak yarı yarıya cevap vermiștir. Bu soruda 259 kiși olumsuz yanıt verirken 241 kişi ise olumlu yanıt vermiştir. Araştırmalarını internet üzerinden yapan kullanıc1lar ise toplamda $\% 78$ oranla belirgin bir üstünlük sağlamıștır. İnternet üzerinden kitap ve makale okuyanların sayısının yarı yarıya olduğunu düşündüğümüzde ve kullanıcıların lise ağırlıklı olduğu göz önüne alındığında, bu araştırmaların daha çok ödev vb. gibi araştırmalar olduğu düşünülebilir(Şekil 4).

\section{Internet ortamındaki bilgileri güvenli bulurum}

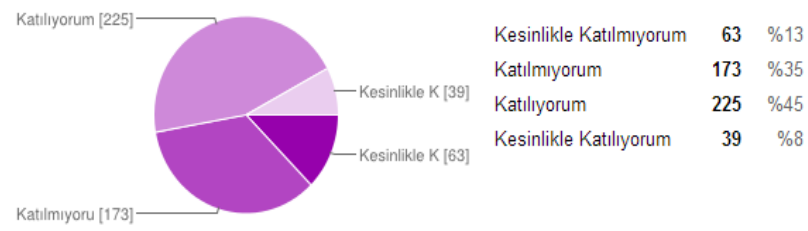

İnternette kendime ait döküman, fotoğraf, video gibi verileri depolarım

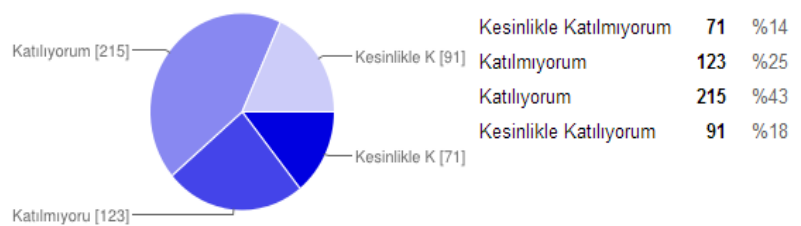

Şekil 5. İnternet ortamına güven (Trust to Internet environment)

İnternet kullanıcılarının yaklaşık \%53'ü şekil 5'te görüldüğü gibi interneti güvenli bulmaktadır. Diğer taraftan $\% 61$ oranda kullanıcı internette doküman, fotoğraf ve video gibi verilerini depolamaktadır. Sosyal paylaşım sitelerine ilgi yoğunlaştıkça, bu oranın daha da artacağı düşünülmektedir. Buradan da anlaşıldığı gibi internet ortamı kullanıcılar tarafından pek de güvenli bir ortam gibi görülmemektedir. Kullanıcıların yarısına yakını bu konuda tereddüt sahibidir.

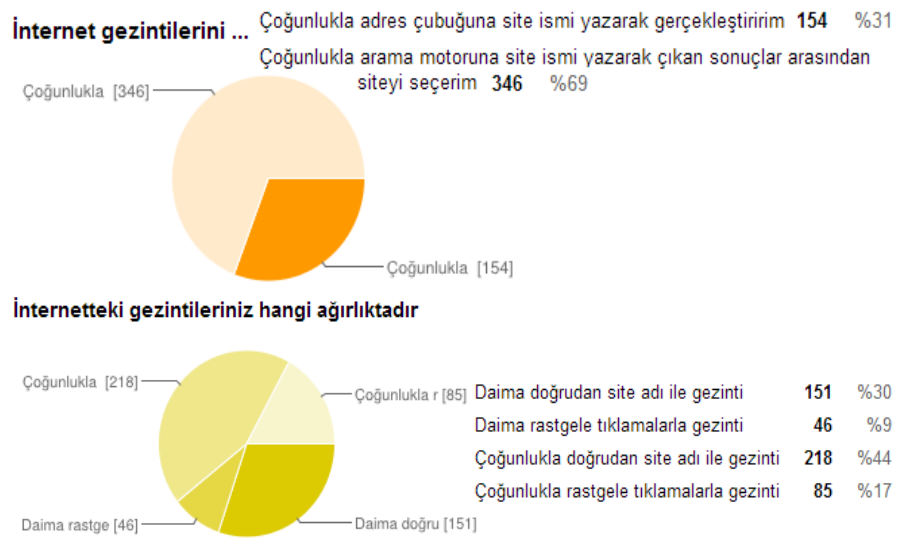

Şekil 6. İnternet üzerinde gezinti durumu (Navigation situation on the Internet)

Şekil 6'da görüldüğü gibi internet kullanıcılarının gezintileri incelendiğinde, ağırlığı doğrudan site adı ile yapılan gezintiler almaktadır. Ayrıca kullanıcılar \%69 oranla, arama motoru ile internet sitelerine girdiklerini belirtmişlerdir.

Ziyaret ettiğiniz site adreslerine dikkat eder misiniz (Alan adı, uzantısı vb.)?

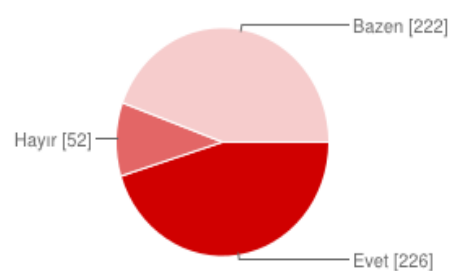

$$
\begin{array}{lrr}
\text { Evet } & 226 & \% 45 \\
\text { Hayır } & 52 & \% 10 \\
\text { Bazen } & 222 & \% 44
\end{array}
$$

Şekil 7. Alan adı ve uzantılarına dikkat (Attention to domain names and extensions)

Ankete katılan kullanıcılardan toplamda \%90’1 daima veya bazen, internette ziyaret ettikleri sitelerin alan adlarına ve uzantılarına dikkat ettiklerini belirtmişlerdir (Şekil 7). Bu da gerçekleştirilen bu çalışmanın asıl amacını destekler niteliktedir.

\section{Aşağıdaki arama motoru adreslerinden hangisi tercih ederdiniz?}

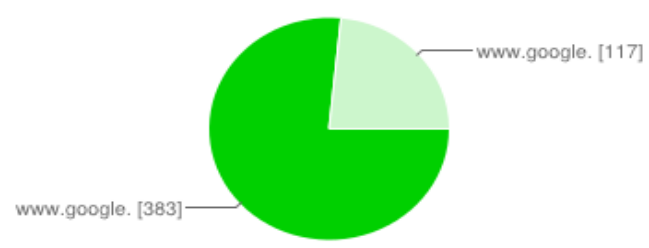

$\begin{array}{lll}\text { www.google.tr } & 383 & \% 77 \\ \text { www.google.com.tr } & 117 & \% 23\end{array}$

Şekil 8. Uzantı tercihleri (Extension preferences)

İnternet kullanıcılarına, en çok bilinen arama motoru adresi üzerinden uzantı sorusu sorulmuştur. Şekil 8'de görüldüğü gibi $\% 77$ oranla kullanıcılar google.tr uzantısını seçerek olmasını istedikleri uzantı modelini 
belirtmişlerdir. Burada belirtmekte fayda görülen bir konu, www.google.tr şeklinde bir alan olmadığıdır. Anketi cevaplandiran gruba bu konu hakkında bilgi verilmiştir. Alan adına dikkat eden bir anket grubunu düşündüğümüzde, bu tercihin ne kadar bilinçli olduğunu da anlamak mümkündür. 383 kullanıcı bu yönde fikir belirterek “.tr" uzantısını doğrudan kullanmayı tercih etmiştir.

Anket sorularının birbirleriyle olan ilişkilerini incelemek amacıyla korelasyon(ilişki) analizleri gerçekleştirilmiştir. İlk olarak kullanıcıların interneti kullanım amaçlarıyla, internette kendilerine ait doküman, fotoğraf, video gibi verileri depolamaları arasındaki ilişkiler incelenmiştir.

Tablo 4. İş amaçlı kullanım ve veri depolama korelasyonu (Business purposes and data storage correlation)

\begin{tabular}{|c|c|c|c|}
\hline \multicolumn{4}{|c|}{ Korelasyonlar } \\
\hline & & $\begin{array}{l}\text { İnterneti iş } \\
\text { amaçlı } \\
\text { kullanıyorum }\end{array}$ & $\begin{array}{l}\text { İnternette } \\
\text { kendime ait } \\
\text { döküman, } \\
\text { fotoğraf, video } \\
\text { gibi verileri } \\
\text { depolarım } \\
\end{array}$ \\
\hline \multirow{3}{*}{$\begin{array}{l}\text { İnterneti iş } \\
\text { amaçlı } \\
\text { kullanıyorum }\end{array}$} & \begin{tabular}{|l} 
Pearson \\
Korelasyonu
\end{tabular} & 1 &, $177 * *$ \\
\hline & $\begin{array}{l}\text { Sigma (çift } \\
\text { kuyruklu) }\end{array}$ & & ,000 \\
\hline & Eleman Sayıs1 & 500 & 500 \\
\hline \multirow{3}{*}{$\begin{array}{l}\text { İnternette } \\
\text { kendime ait } \\
\text { döküman, } \\
\text { fotoğraf, video } \\
\text { gibi verileri } \\
\text { depolarım }\end{array}$} & \begin{tabular}{|l} 
Pearson \\
Korelasyonu
\end{tabular} &, $177 * *$ & 1 \\
\hline & $\begin{array}{l}\text { Sigma (çift } \\
\text { kuyruklu) }\end{array}$ & ,000 & \\
\hline & Eleman Sayıs1 & 500 & 500 \\
\hline
\end{tabular}

Tablo 5. Sosyal/eğlence kullanımı ve veri depolama (Social/entertainment usage and data storage)

\begin{tabular}{|c|c|c|c|}
\hline \multicolumn{4}{|c|}{ Korelasyonlar } \\
\hline & & $\begin{array}{l}\text { İnternette } \\
\text { kendime ait } \\
\text { döküman, } \\
\text { fotoğraf, video } \\
\text { gibi verileri } \\
\text { depolarım }\end{array}$ & $\begin{array}{c}\text { İnterneti } \\
\text { sosyal/eğlence } \\
\text { amaçlı } \\
\text { kullanıyorum }\end{array}$ \\
\hline \multirow{3}{*}{$\begin{array}{l}\text { İnternette } \\
\text { kendime ait } \\
\text { döküman, } \\
\text { fotoğraf, video } \\
\text { gibi verileri } \\
\text { depolarım } \\
\end{array}$} & \begin{tabular}{|l} 
Pearson \\
Korelasyonu \\
\end{tabular} & 1 &, $181 * *$ \\
\hline & $\begin{array}{l}\text { Sigma (çift } \\
\text { kuyruklu) }\end{array}$ & & ,000 \\
\hline & Eleman Sayı1s1 & 500 & 500 \\
\hline \multirow{3}{*}{$\begin{array}{l}\text { İnterneti } \\
\text { sosyal/eğlence } \\
\text { amaçlı } \\
\text { kullanıyorum }\end{array}$} & $\begin{array}{l}\text { Pearson } \\
\text { Korelasyonu } \\
\end{array}$ &, $181 * *$ & 1 \\
\hline & $\begin{array}{l}\text { Sigma (çift } \\
\text { kuyruklu) }\end{array}$ & ,000 & \\
\hline & Eleman Sayısı & 500 & 500 \\
\hline
\end{tabular}

Tablo 6. Eğitim amaçlı kullanım ve veri depolama (Education purpose usage and data storage)

\begin{tabular}{|l|l|c|c|}
\hline \multicolumn{4}{|c|}{ Korelasyonlar } \\
\hline \multicolumn{2}{|c|}{} & $\begin{array}{c}\text { İnterneti eğitim } \\
\text { amaçlı } \\
\text { kullanıorum }\end{array}$ & $\begin{array}{c}\text { Internette kendime } \\
\text { ait döküman, } \\
\text { fotoğraf, video gibi } \\
\text { verileri depolarım }\end{array}$ \\
\hline $\begin{array}{l}\text { İnterneti eğitim } \\
\text { amaçlı }\end{array}$ & $\begin{array}{l}\text { Pearson } \\
\text { Korelasyonu }\end{array}$ & 1 &, 079 \\
\hline
\end{tabular}

\begin{tabular}{|c|c|c|c|}
\hline \multirow[t]{2}{*}{ kullanıyorum } & \begin{tabular}{|l|} 
Sigma (çift \\
kuyruklu)
\end{tabular} & & ,079 \\
\hline & Eleman Say1s1 & 500 & 500 \\
\hline \multirow{3}{*}{$\begin{array}{l}\text { Internette } \\
\text { kendime ait } \\
\text { döküman, } \\
\text { fotoğraf, video } \\
\text { gibi verileri } \\
\text { depolarım }\end{array}$} & \begin{tabular}{|l|} 
Pearson \\
Korelasyonu
\end{tabular} & ,079 & 1 \\
\hline & $\begin{array}{l}\text { Sigma (çift } \\
\text { kuyruklu) }\end{array}$ & ,079 & \\
\hline & Eleman Sayısı & 500 & 500 \\
\hline
\end{tabular}

Tablo 4'te interneti iş amaçlı kullanan kullanıcılar ile internette kendine ait verileri depolayan kullanıcılar arasındaki iki yönlü korelasyon (ilişki) görünmektedir. r= ,177 olduğu için pozitif yönde zayıf bir ilişki vardır. Tablo 5'te interneti sosyal/eğlence amaçlı kullanan kullanıcılar ile internette kendine ait verileri depolayan kullanıcılar arasındaki iki yönlü korelasyon (ilişki) görünmektedir. $r=, 181$ olduğu için pozitif yönde zayıf bir ilişki vardır. Burada özellikle günümüzde sosyal medya sitelerinde paylaşılan resim ve videolar gibi veriler göz önüne alındığında, bu ilişkinin daha yüksek oranda olması beklenmiştir. Tablo 6'da ise interneti eğitim amaçlı kullanan kullanıcılar ile internette kendine ait verileri depolayan kullanıcılar arasındaki iki yönlü korelasyon (ilişki) görünmektedir. $r=, 079$ olduğu için pozitif yönde zayıf bir ilişki vardır.

Tablo 4, Tablo 5 ve Tablo 6 korelasyonları incelendiği zaman internet kullanım amacının, kullanıcıların internet üzerinde kendilerine ait döküman, fotoğraf, video gibi verileri depolamalarına çok az etki ettiği görülmektedir. Bunun sonucunda ise kullanıcıların anketteki "veri depolama" kavramına yönelik algılarının ne olduğu sorusu ortaya çıkmıştır. Buradaki depolama kavramı, sosyal medya sitelerindeki paylaşımlar haricinde düşünülerek, bulut sistemler, mail ve internette disk alanları gibi hizmetlerin akla geldiği tahmin edilmiştir.

Tablo 7. İnternete güven ve veri depolama korelasyonu (Internet trust and data storage correlation)

\begin{tabular}{|c|c|c|c|}
\hline \multicolumn{4}{|c|}{ Korelasyonlar } \\
\hline & & $\begin{array}{l}\text { İnternette } \\
\text { kendime ait } \\
\text { döküman, } \\
\text { fotoğraf, video } \\
\text { gibi verileri } \\
\text { depolarım }\end{array}$ & $\begin{array}{l}\text { İnternet ortamindaki } \\
\text { bilgileri güvenli } \\
\text { bulurum }\end{array}$ \\
\hline \multirow{3}{*}{$\begin{array}{l}\text { Internette } \\
\text { kendime ait } \\
\text { döküman, } \\
\text { fotoğraf, video } \\
\text { gibi verileri } \\
\text { depolarım } \\
\end{array}$} & $\begin{array}{l}\text { Pearson } \\
\text { Korelasyonu }\end{array}$ & 1 &, $165 * *$ \\
\hline & $\begin{array}{l}\text { Sigma (çift } \\
\text { kuyruklu) }\end{array}$ & & ,000 \\
\hline & Eleman Sayısı & 500 & 500 \\
\hline \multirow{3}{*}{$\begin{array}{l}\text { Internet } \\
\text { ortamındaki } \\
\text { bilgileri güvenli } \\
\text { bulurum }\end{array}$} & \begin{tabular}{|l} 
Pearson \\
Korelasyonu
\end{tabular} &, $165 * *$ & 1 \\
\hline & $\begin{array}{l}\text { Sigma (çift } \\
\text { kuyruklu) }\end{array}$ & ,000 & \\
\hline & Eleman Sayıs1 & 500 & 500 \\
\hline
\end{tabular}

Tablo 7'de İnternet ortamındaki bilgileri güvenli bulan kullanıcılar ile internette kendine ait verileri depolayan kullanıcılar arasındaki iki yönlü korelasyon (ilişki) görünmektedir. $r=, 165$ olduğu için pozitif yönde zayıf bir ilişki vardır. Kullanıcıların internet ortamındaki bilgileri güvenli bulmaları, internet üzerinde kendilerine ait döküman, fotoğraf, video gibi verileri depolamalarına çok 
az etki etmektedir. Bu da kullanıcıların internet ortamın güvenli bulsalar dahi veri depolamaya yönelik tercihlerini kişisel bilgisayarlarından yana kullandıklarını ortaya çıkarmıştır.

Tablo 8. İnternette araştırma ve veri depolama (Research on Internet and data storage)

\begin{tabular}{|c|c|c|c|}
\hline \multicolumn{4}{|c|}{ Korelasyonlar } \\
\hline & & $\begin{array}{c}\text { Araştırmalarım } \\
1 \text { internet } \\
\text { üzerinden } \\
\text { yaparım }\end{array}$ & $\begin{array}{c}\text { İnternet } \\
\text { ortamındaki } \\
\text { bilgileri güvenli } \\
\text { bulurum }\end{array}$ \\
\hline \multirow{3}{*}{$\begin{array}{l}\text { Araştırmalarımı } \\
\text { internet } \\
\text { üzerinden } \\
\text { yaparım }\end{array}$} & \begin{tabular}{|l} 
Pearson \\
Korelasyonu
\end{tabular} & 1 & ,191** \\
\hline & $\begin{array}{l}\text { Sigma (çift } \\
\text { kuyruklu) }\end{array}$ & & ,000 \\
\hline & Eleman Sayısı & 500 & 500 \\
\hline \multirow{3}{*}{$\begin{array}{l}\text { İnternet } \\
\text { ortamındaki } \\
\text { bilgileri güvenli } \\
\text { bulurum }\end{array}$} & \begin{tabular}{|l|} 
Pearson \\
Korelasyonu
\end{tabular} &, $191 * *$ & 1 \\
\hline & $\begin{array}{l}\text { Sigma (çift } \\
\text { kuyruklu) }\end{array}$ &, 000 & \\
\hline & Eleman Sayısı & 500 & 500 \\
\hline
\end{tabular}

Tablo 8'de İnternet ortamındaki bilgileri güvenli bulan kullanıcılar ile araştırmalarını internet üzerinden yapan kullanıcılar arasındaki iki yönlü korelasyon (ilişki) görünmektedir. $r=, 191$ olduğu için pozitif yönde zayıf bir ilişki vardır. Kullanıcıların internet ortamındaki bilgileri güvenli bulmaları, araştırmalarını internet üzerinden yapmalarına çok az etki etmektedir. Güven ve araştırma korelasyonu göstermiştir ki, internette araştırma yapan kullanıcılar, güven etkeninden daha çok başka etkenler ile araştırmalarını gerçekleştirmektedirler.

Tablo 9. Tek yönlü varyans analizleri (ANOVA) (One-way variance analysis (ANOVA))

A) Eğitim Durumu ve Arama Motoru Adresi Tercihi Așağıdaki arama motoru adreslerinden hangisi tercih ederdiniz?

\begin{tabular}{|l|c|c|c|c|c|}
\hline & $\begin{array}{c}\text { Kareler } \\
\text { Toplamı }\end{array}$ & df & $\begin{array}{c}\text { Kare } \\
\text { Ortalama }\end{array}$ & $\mathrm{F}$ & Sigma \\
\hline $\begin{array}{l}\text { Gruplar } \\
\text { Arası }\end{array}$ & 16,883 & 4 & 4,221 & 28,723 &, 000 \\
\hline Gruplar İçi & 72,739 & 495 &, 147 & & \\
\hline Toplam & 89,622 & 499 & & & \\
\hline
\end{tabular}

B) İnternet Kullanma Sıklığı ve Arama Motoru Adresi Tercihi

Aşağıdaki arama motoru adreslerinden hangisi tercih ederdiniz?

\begin{tabular}{|l|c|c|c|c|c|}
\hline & $\begin{array}{c}\text { Kareler } \\
\text { Toplamı }\end{array}$ & df & $\begin{array}{c}\text { Kare } \\
\text { Ortalama }\end{array}$ & F & Sigma \\
\hline $\begin{array}{l}\text { Gruplar } \\
\text { Arası }\end{array}$ & 3,374 & 5 &, 675 & 3,865 &, 002 \\
\hline Gruplar İçi & 86,248 & 494 &, 175 & & \\
\hline Toplam & 89,622 & 499 & & & \\
\hline
\end{tabular}

C) Yaș ve Arama Motoru Adresi Tercihi Aşağıdaki arama motoru adreslerinden hangisi tercih ederdiniz?

\begin{tabular}{|l|c|c|c|c|c|}
\hline & $\begin{array}{c}\text { Kareler } \\
\text { Toplamı }\end{array}$ & df & $\begin{array}{c}\text { Kare } \\
\text { Ortalama }\end{array}$ & F & Sigma \\
\hline $\begin{array}{l}\text { Gruplar } \\
\text { Arası }\end{array}$ & 17,273 & 7 & 2,468 & 16,780 &, 000 \\
\hline Gruplar İçi & 72,349 & 492 &, 147 & & \\
\hline Toplam & 89,622 & 499 & & & \\
\hline
\end{tabular}

Tablo 9 A, B ve C'de internet kullanıcılarının arama motoru adresi tercihlerinin, demografik özelliklerine göre anlamlı bir farklılık gösterip göstermediğini belirlemek amacıyla yapılan tek yönlü varyans analizi (ANOVA) sonuçları görülmektedir. Tablo 9A'da $\mathrm{F}=28,723$ ve $\mathrm{p}=, 000<0,05$, Tablo 9B'de $\mathrm{F}=3,865$ ve $\mathrm{p}=, 002<0,05$, Tablo 9C'de ise $\mathrm{F}=16,780$ ve $\mathrm{p}=, 000<0,05$ olarak hesaplanmıştır. $\mathrm{Bu}$ durumda internet kullanıcılarının arama motoru adresi tercihleri ile demografik özellikleri arasında anlamlı bir farklılık olduğu ortaya çıkmıştır.

\section{SONUÇLAR VE ÖNERILER (CONCLUSIONS AND SUGGESTIONS)}

$\mathrm{Bu}$ çalışmada internet alan adları konusunda değinilmiş ve Türkiye'de kullanılan ikincil düzey alan adları sistemi incelenmiş ve Türkiye'deki internet kullanıcılarının tercihleri incelenmiştir. Alan adı modelleri tanımlanmış ve Türkiye'de neden ikincil düzey alan adı sistemi kullanıldığı açıklanmıştır. 1990 yılında TÜVAKA tarafindan alınan karar sonrasında kullanılmakta olan alan adı sistemi, internet kullanıcılarının akıllarında soru işaretleri oluşturmaktadır çünkü “.com” uzantısı ABD'ye ait bir uzantıdır. Türkiye'deki bazı şirketler, "com.tr" uzantısını uzunluğundan dolayı tercih etmeyerek ".com" uzant1lı adresler almaktadır. $\mathrm{Bu}$ durumda firmalar Türkiye'de olsa da dişardan bakıldığında alan adı, ABD'ye ait bir alan gibi görülmektedir. Buradan yola çıkarak ülkemizde de artık ülke kodu birinci derece alan adı sisteminin kullanılabilmesi önerilmiştir. Hatta ihtiyaç halinde bazı kurumlara ayrıcalık tanınarak jenerik birinci derece alan adını kullanmalarını sağlayan hibrid bir sistem de kullanılabilir. Yani istenildiğinde ".tr" istenildiğinde ise ".com.tr" alan adı kullanılabilmelidir. Ayrıca bazı kurumlar için "gov.tr, edu.tr vb." gibi uzantıların kullanımına devam edilebilir. Alan adı algısını araştırmak üzere 500 internet kullanıcısına(\%68 oranda her gün internet kullanan) uygulanan anket sonucunda $\% 90$ oranda alan adına dikkat edildiği sonucuna ulaşılmıştır. Böyle yüksek oranda alan adına dikkat eden kullanıcılardan \%77'si ülke kodu birinci derece alan adını tercih etmişlerdir. Buradan yola çıkarak, 1990 yılında alınan kararın artık günümüzdeki kullanıcıların algılarını karşılamadığını söylemek mümkündür. Karar yetkisini elinde bulunduran kurumlara ülke çapında daha kapsamlı ve geniş katılımlı anket uygulaması gerçekleştirerek, elde edilen verilerle birlikte alan ad1 sisteminin yeniden görüşülmesi önerilmektedir.

Anket sorularının korelasyonları sonucunda internet kullanıcılarının interneti kullanım amaçlarının, internette veri depolama işlemlerine etkisinin çok az olduğu ortaya çıkmıştır. Buradan da ülkemizdeki internet kullanıcılarının, günümüzde gittikçe önem kazanan bulut bilişim sistemlerine yönelik daha fazla bilgilendirilmesi gerektiği sonucu ortaya çıkmıştır. Diğer bir taraftan her geçen gün önemi daha da artan büyük veri(big data) kavramı göstermektedir ki, internette veri akışı çok büyük boyutlara ulaşmıştır. Sosyal medya sitelerinde paylaşılan fotoğraf ve videolar da internet üzerinde depolanan, kullanıcı hesaplarına bağlı veriler olarak düşünülebilir. 
İnternet kullanıcılarının kişisel verilerini internet üzerinde depoladıkları bilinmekte ve gelecekte de depolamaya medya ve büyük veri konularında daha fazla araştırma ve yayın ile bilgilendirilmesi gerekmektedir. Bu bağlamda internet kullanıcılarına yönelik gelecekte yapılacak çalışmalara da belirtilen alanlar önerilmektedir.

\section{KAYNAKLAR (REFERENCES)}

[1] Türkiye Elektronik Haberleşme Sektörü, Üc Aylık Pazar Verileri Raporu 2014 yılı 3. Çeyrek, Sektörel Araştırma ve Strateji Geliştirme Dairesi Başkanlığı, Bilgi Teknolojileri ve İletişim Kurumu, 37-38, Ankara, 2014.

[2] Y. Koç, A. Jamakoviç, B. Gijsen,"A global reference model of the domain name system", International Journal of Critical in Frastructure Protection, 5, 108-117, 2012.

[3] Alexa-Actionable Analytics for the Web, http://www.alexa.com, 26.10.2013.

[4] “.tr” Alan Adları, Politikalar, Kurallar ve İşleyiş - Sürüm 5.1.2, NIC.TR “.tr” Alan Adları Yönetimi, 2, 2012.

[5] S. Bozbel, İnternet Alan Adlarmın (Domain Names) Korunmasında ICANN Tahkim Usulü, Seçkin Yayıncılık, Ankara, 2006.

[6] G. Anık, “İnternet Alan Adı", AB Fikrî Mülkiyet ve Rekabet Hukuku Dergisi, 5(4), 65-93, 2005.

[7] N. Bal, "İnternet Alan Adları Ve İnternet Alan Adı Uyuşmazlıklarının Tahkim Yoluyla Çözümlenmesi”, Gazi Üniversitesi Hukuk Fakültesi Dergisi, 17(1-2), 4, 2013.

[8] MEGEP, Hayatboyu Öğrenme Genel Müdürlüğü Modüller, http://hbogm.meb.gov.tr/modulerprogramlar/kursprogramlari/bilisi m/moduller/TCPiP_ve_iP_adresleme.pdf, 04.01.2015.

[9] E. Casalicchio, M. Caselli, A. Coletta, "Measuring The Global Domain Name System”, Network, IEEE, 27(1), 28, 2013.

[10] ICANN Archives, http://archive.icann.org/tr/turkish.html, 26.10.2013.

[11] Y. Kaplan, "İnternet Alan İsimlerine İlişkin Uluslararası Uyuşmazlıkların Çözümü Konusunda ICANN Yargılama Usulü”, Cumhuriyetimizin 80. Kuruluş Yılına Armağan, AÜEHFD, 7(3-4), 699-720, 2003 devam edecekleri öngörülmektedir. Ülkemizde internet kullanıcılarının bulut bilişim, siber güvenlik, sosyal

[12] S. Bozbel, Internet Alan Adı (domain name) Tescil Uygulamalar ve Yeni Öneriler, http://www.e-akademi.org/makaleler/sbozbel3.htm, 26.10.2013.

[13] B. Yazıcı, Bahaddin Yazıcı Kişisel Web Sitesi, http://bahaddinyazici.com/76_icerik-neden--tr-uzantili-bir-alanadimiz-yok.aspx, 04.01.2015.

14] Neden "tr" yerine "com.tr"? http://forum.donanimhaber.com/m_65551160/tm.htm, 04.01.2015.

[15] Türkiye Neden Kendi Uzantısını Kullanmıyor? - Google Fan Webmaster Forum, http://www.r10.net/domain-genel/804500turkiye-neden-kendi-uzantisini-kullanmiyor.html, 04.01.2015.

[16] Neden “com.tr"?, http://www.pcnet.com.tr/forum/internet-ag-veguvenlik/174932-neden-com-tr.html, 04.01.2015.

[17] B. Akmenek, Neden com.tr uzantısını kullanıyoruz? - Fragtist, http://fragtist.com/sozluk/neden-com-tr-uzantisini-kullaniyoruz, 04.01 .2015

[18] Neden $\operatorname{Tr}$ Yok?, http://www.webmastersitesi.com/domainsohbet/719310-neden-tr-yok.htm, 04.01.2015.

[19]Bizim niye (.tr) uzantımız yok, http://www.turkeyforum.com/satforum/showthread.php?t=304806\#. VKmTzyusXa4, 04.01.2015.

[20]Bizim Neden Tr Uzantılı Alan Adımız Yok? WM Aracı, http://wmaraci.com/forum/alan-adi-bilgi-alisverisi/tr-uzantili-alanadimiz-yok-196791.html, 04.01.2015.

[21] http://www.inploid.com/t/bazi-yabanci-siteler-de-ru-gibi-uzantiyasahip-turkiyede-neden-tr-yok-da-comtr-nettr-filan-gibi-uzantilarvar/41502/, 04.01.2015

[22] Neden com.tr? Neden .tr değil?, http://www.ytpara.com/konudisi/34866-neden-com-tr-neden-tr-degil.html, 04.01.2015.

[23] A. C. Şit, .TC uzantısının perde arkası, http://www.webrazzi.com/2012/12/07/tc-alan-adi-uzantisinin-perdearkasi/, 26.10.2013.

[24] Ö. Cetin, .TC uzantısı yeniden geliyor - Shiftdelete.NET, http://shiftdelete.net/.tc-uzantisi-yeniden-geliyor-40874.html, 26.10 .2013 